\title{
Role of mammography to assess complications of silicone gel breast implants
}

Walter Peters PhD MD FRCSC, Dennis Smith PhD DSc FRCS, Harvey Grosman MD FRCPC, Victor Fornasier MD FRCPC

Divisions of Plastic Surgery, Radiology, and Pathology, Wellesley Hospital, Toronto, and the Centre for Biomaterials, University of Toronto, Toronto, Ontario

W Peters, D Smith, H Grosman, V Fornasier. Role of mammography to assess complications of silicone gel breast implants. Can J Plast Surg 1995;3(3):150-156. Mammography is not accurate to predict implant rupture in most patients. Its sensitivity rate is only 11 to $16 \%$. However, two mammographic findings appear to suggest implant rupture: the appearance of large areas of implant herniation, and the appearance of silicone globules lying outside the margins of the implant. Mammography is also helpful to predict capsular calcification and to assess certain complications of retained breast implant capsules. Two patients presented with retained capsules which had not resolved, two and five years after implant removal. One patient developed a spiculated mass, suspicious for carcinoma, that proved to be a cystic mass resulting from persistent serous effusion. The other patient demonstrated a large densely calcified capsule which interfered with breast imaging.

Key Words: Breast implant rupture, Mammography, Silicone gel breast implants

Rôle de la mammographie dans l'évaluation des complications des implants au gel de silicone

RÉSUMÉ: La mammographie reste imprécise chez la plupart des patientes lorsqu'il est question de prévoir la rupture d'un implant. Son taux de sensibilité n'est que de 11/16. Toutefois, deux observations à la mammographie semblent suggérer la rupture de l'implant : l'apparition de grandes zones herniées de l'implant et l'apparition de globules de silicone à l'extérieur du rebord de l'implant. La mammographie est également utile pour prédire la calcification capsulaire et pour en évaluer les complications. Deux patientes se sont présentées avec des capsules de rétention persistantes, deux et cinq ans respectivement après le retrait de l'implant. Une patiente a développé une masse à épines, évocatrice d'un carcinome, qui s'est révélé être une masse kystique résultant d'un épanchement séreux persistant. L'autre patiente présentait une volumineuse capsule densément calcifiée qui interférait avec la visualisation du sein. 
Over the years, two radiological techniques have been employed for imaging breasts with silicone implants -- xeroradiography and film-screen mammography. Xeroradiography produces an image on the film electrically rather than chemically. It is less sensitive to subtle density differences, and requires higher radiation doses than film-screen mammography. Xeroradiography units are no longer being manufactured and repairs to these older units are therefore becoming more difficult. Over $95 \%$ of mammography centres in North America have now converted from xeroradiography to film-screen mammography.

\section{MAMMOGRAM TECHNIQUE}

In patients without breast implants, screening mammography usually involves two views: a mediolateral oblique (MLO) view, in which the breast is viewed from side to side; and a craniocaudal (CC) view, in which the breast is viewed from top to bottom. In patients with silicone breast implants, however, about $38 \%$ of the glandular tissue is obscured by the implant if only these views are used (1). To improve imaging in these patients, Eklund (2) developed the push-back (implant displacement) technique, wherein the breast tissue is pulled anteriorly away from the breast implant, and compressed between the x-ray film holder and the paddle. The same two views (MLO and CC) are then performed using this technique. Most mammography centres recommend this fourview mammogram in all patients with breast implants. This allows more breast tissue to be visualized on the mammogram. Most patients find that the Eklund technique is quite uncomfortable. Some patients avoid further mammograms because of the discomfort. It should be recognized that, in spite of the Eklund technique, the amount of breast tissue visualized will still be limited by the implant (3).

Patients often ask if mammography can rupture a breast implant. The potential for this rupture is not known. There are no documented cases of rupture due to mammography in the American literature (4). However, the potential for rupture has resulted in a signed consent form which is used in some mammography centres in the United States before mammography.

\section{MATERIALS AND METHODS}

The purpose of this study was to analyze the role of mammography in assessing breasts with silicone gel breast implants. During the past four years, more than 700 patients with silicone gel breast implants have been clinically assessed in our clinic. These patients were either self-referred or physician-referred to a clinical plastic surgery practice. All patients sought further consultations regarding the status of their implants. Eighty-three patients underwent implant removal. Of these patients, about one-third had undergone mammography. A retrospective analysis of these mammograms indicated that mammography appeared to have a role, in certain patients, to predict implant rupture, capsular calcification and complications from retained capsules.

\section{Implant rupture}

\section{RESULTS}

Mammography is not accurately able to predict implant rupture in the majority of patients $(4,5)$. In spite of this limitation, the current study indicates that two mammographic 
findings suggest implant rupture: major implant herniation and the appearance of silicone globules outside the margin of the implant.

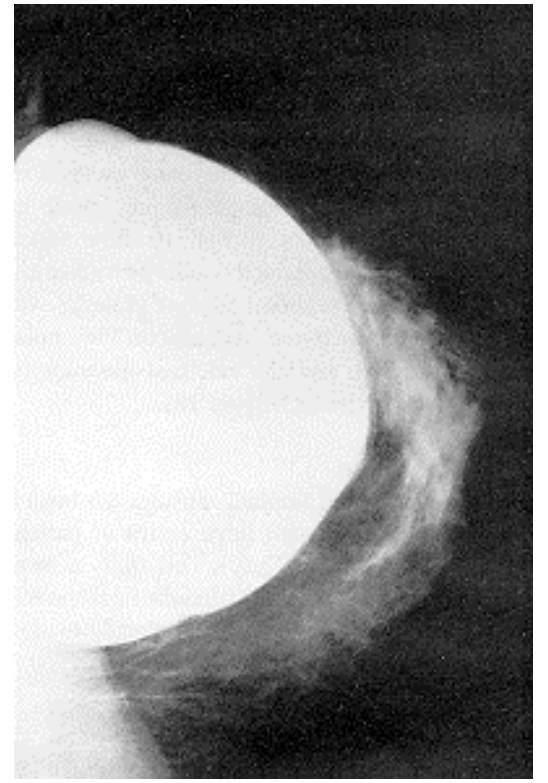

Figure 1) Mammogram showing herniation superiorly and areas of irregularity inferiorly. This implant was intact at surgery

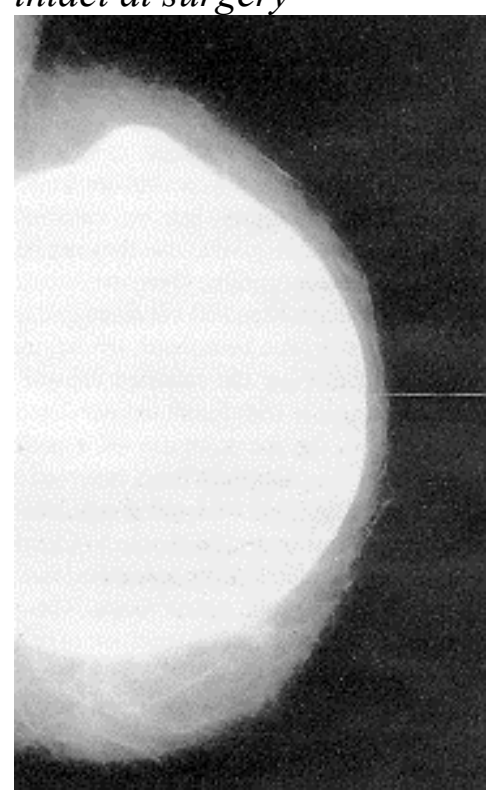

Figure 2) Mammogram showing a small herniation superiorly. This was not present on a mammogram done three years earlier. At surgery, the implant was ruptured at this site

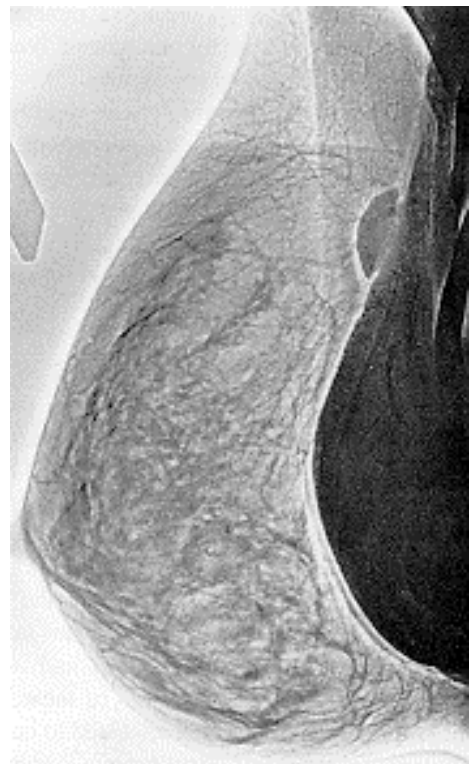

Figure 3) Xeromammogram showing a small area of herniation superiorly. At surgery, the implant was ruptured at this site

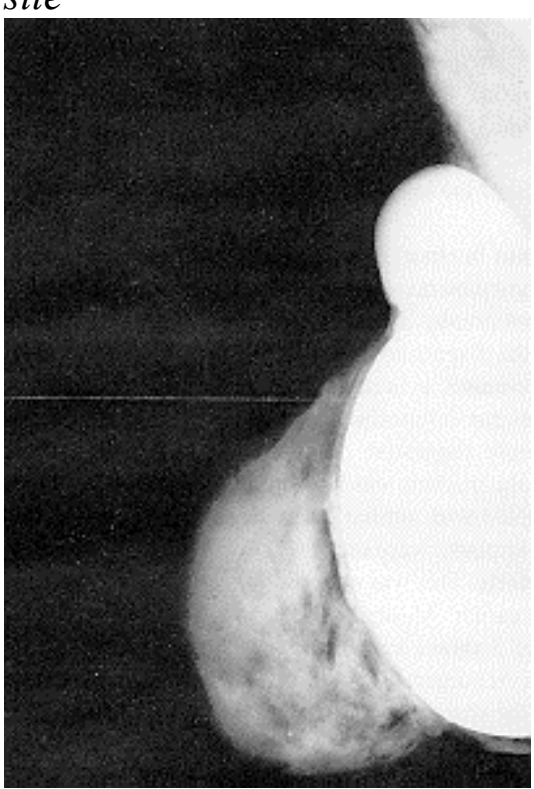

Figure 4) Mammogram showing a large herniation superiorly. This implant was ruptured at surgery 
Peters et al

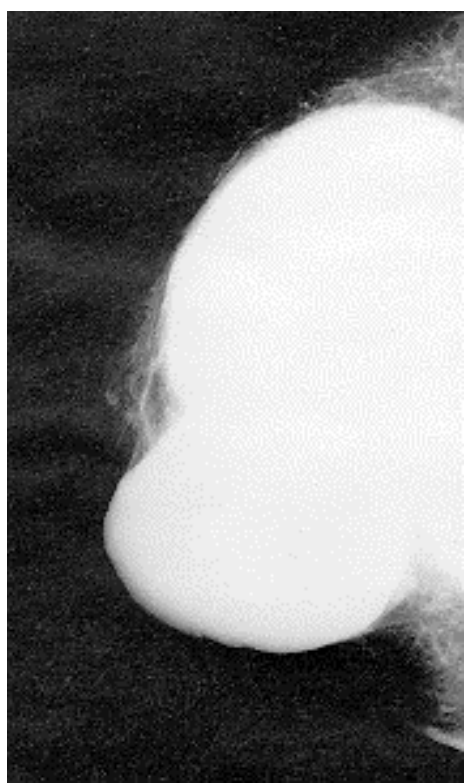

Figure 5) Mammogram showing a huge herniation inferiorly. This implant was ruptured at surgery and the implant wall was torn completely apart

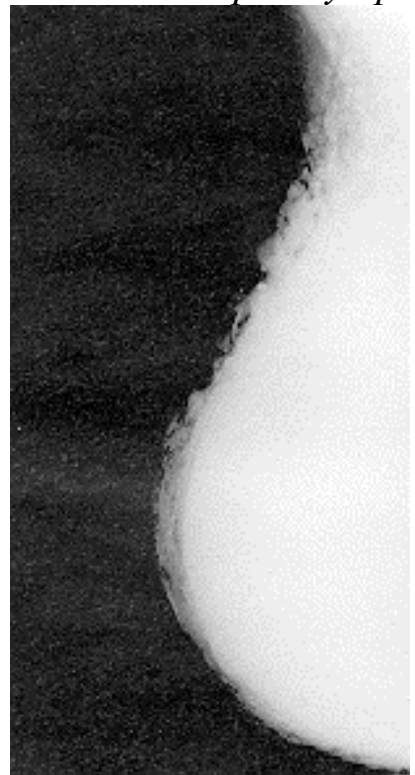

Figure 6) Mammogram showing silicone globules that have escaped from the implant. At surgery, this implant was completely ruptured
Mammography and silicone breast implants

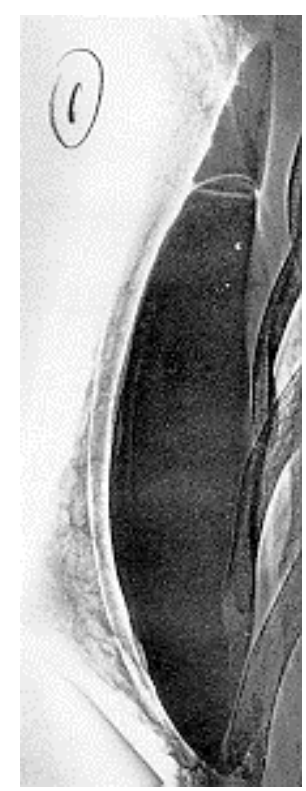

Figure 7) Xeromammogram showing silicone globules that have escaped from the implant superiorly. At surgery, the implant was ruptured at this site

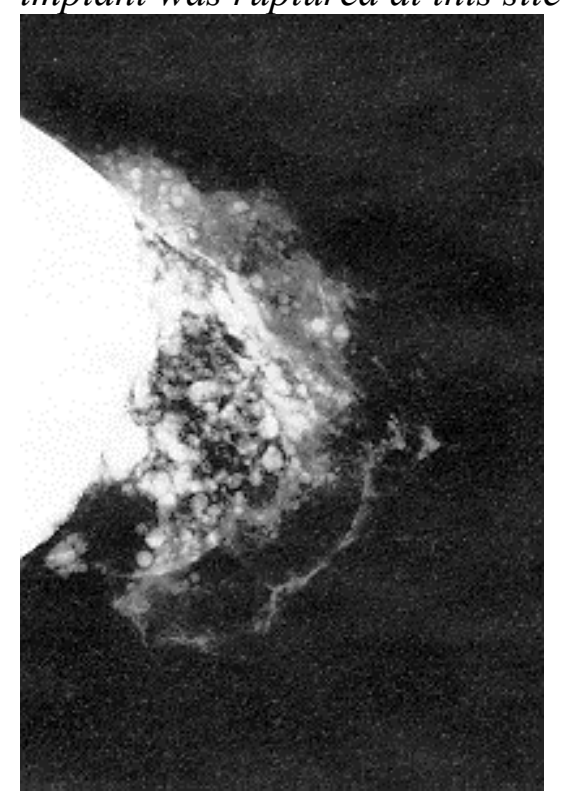

Figure 8) Mammogram showing a large area of calcified globules. At surgery, the implant wall was totally disrupted, and the calcified globules were scattered throughout the breast tissue in this area (see Figure 15) 


\section{Implant herniation}

Eight patients demonstrated areas of implant herniation on mammography. If there were small areas of implant herniation, the diagnosis of implant rupture was uncertain. Figure 1 demonstrates a herniation superiorly and smaller areas of irregularity inferiorly. This was reported by the radiologist as "strongly suggestive of implant rupture". At surgery, however, the implant was fully intact. Several other patients also presented with similar small areas of herniation. At surgery, their implants were intact. Figure 2 shows a small herniation superiorly. This was not present on a mammogram done three years earlier. At surgery, the implant was ruptured at this site. Figure 3 shows a small area of herniation on xeromammogram. At surgery, this implant was also ruptured at this site.

If the size of the herniation was large, implant rupture was more likely. Figure 4 shows a large implant herniation superiorly. At surgery, the implant was ruptured at this site. Figure 5 shows a similar large herniation inferiorly. This implant was also ruptured at this site at surgery.

\section{Silicone globules}

The mammographic appearance of silicone globules, outside the limits of the implant, was indicative of implant rupture. The mammogram in Figure 6 shows multiple areas of silicone globules that have escaped from the radiological outline of the implant. These globules were not present in a mammogram done three years earlier. Figure 7 shows a xeromammogram with globules that have escaped from the superior aspect of the implant. At surgery, these implants were ruptured at these sites. In both of these patients, the silicone globules were contained within the capsules. Figure 8 shows large areas of calcified silicone globules within the substance of the breast tissue. At surgery, the implant wall was totally disrupted, and the calcified globules occurred throughout the breast tissue (Figure 15).

\section{Capsular calcification}

Calcification of breast implant capsules has been demonstrated in 16 to $17 \%$ of two large series of patients with silicone gel breast implants $(7,10)$. This study demonstrated that calcification could often be predicted preoperatively. It presented as areas of stipling on a xeroradiomammogram (Figure 9) and mammogram (Figure 10).

\section{Complications from retained capsules}

Because it has been reported that silicone implant capsules resolve uneventfully (11), and because capsulectomy can increase patient morbidity and cost, many surgeons have elected to leave breast implant capsules in place, when silicone gel breast implants are removed. Recent findings, however, have indicated that uneventful resolution of breast implant capsules may not always occur (12). Certain complications of retained breast capsules can be diagnosed by mammography. 
Peters et al

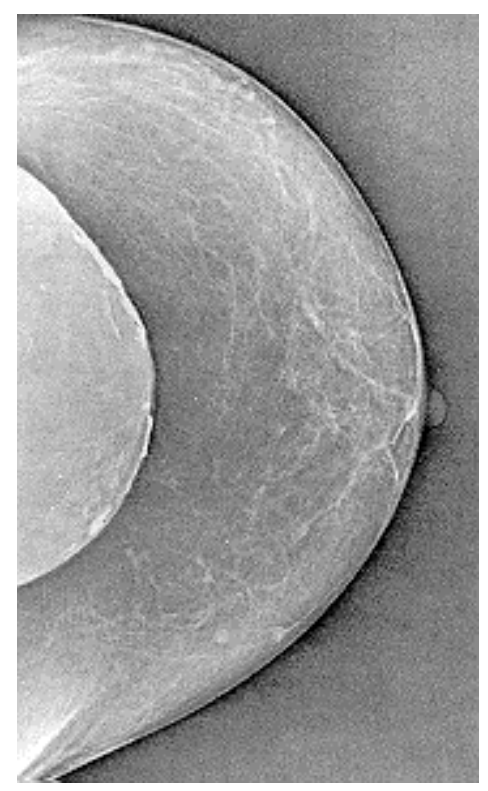

Figure 9) Xeromammogram showing stipling of anterior capsule margins, indicating capsular calcification

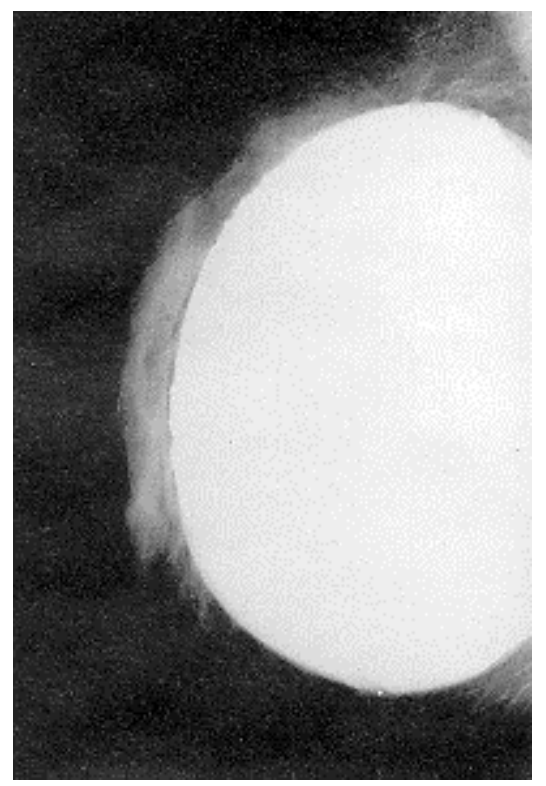

Figure 10) Mammogram showing stipling of anterior capsule margin, indicating calcification
Mammography and silicone breast implants

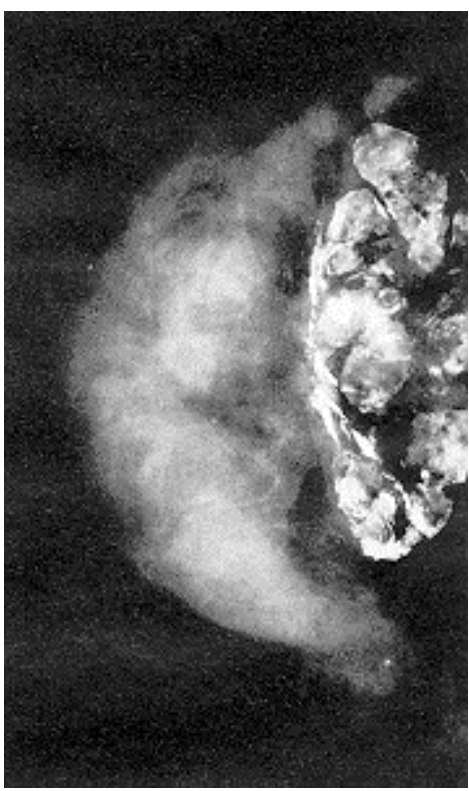

Figure 11) Mammogram showing a large calcified mass posteriorly. This patient's implants had been removed five years previously. The calcified capsules were left in situ. She had requested that they not be excised, to prevent secondary deformity. This area of calcification has persisted

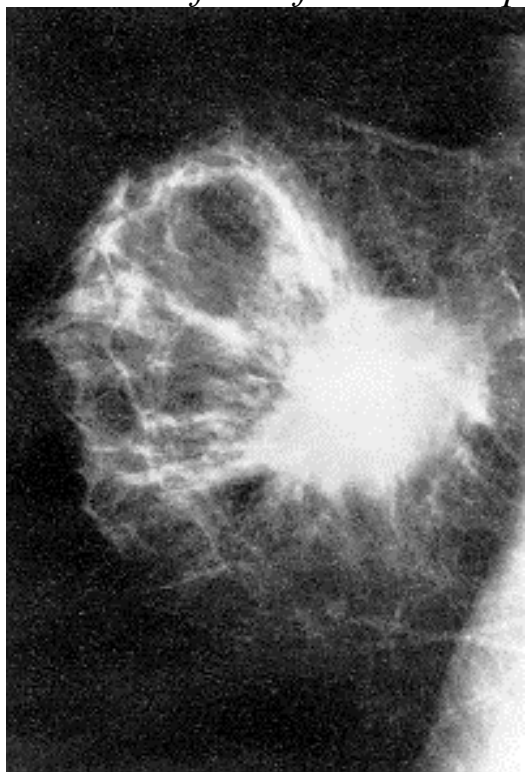

Figure 12) Mammogram showing a dense spiculated $5 \mathrm{~cm}$ mass, located deep in breast tissue, suggestive of malignancy. The patient's silicone gel implants (but not the capsules) had been removed two years previously 


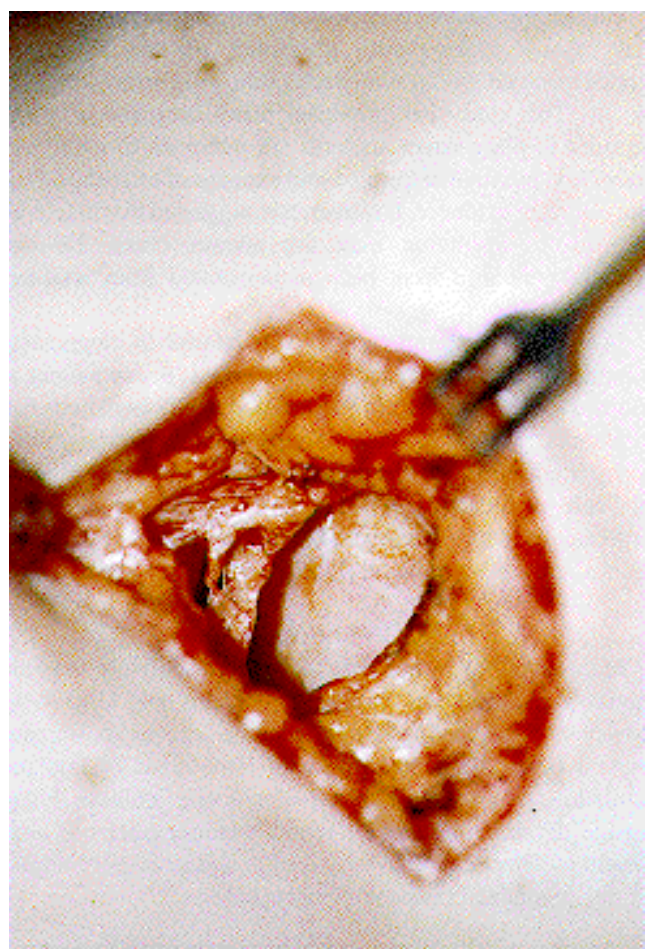

Figure 13) At exploration, the mass shown in Figure 12 demonstrated a thick-walled cystic cavity that contained about $50 \mathrm{~mL}$ of a watery brown fluid

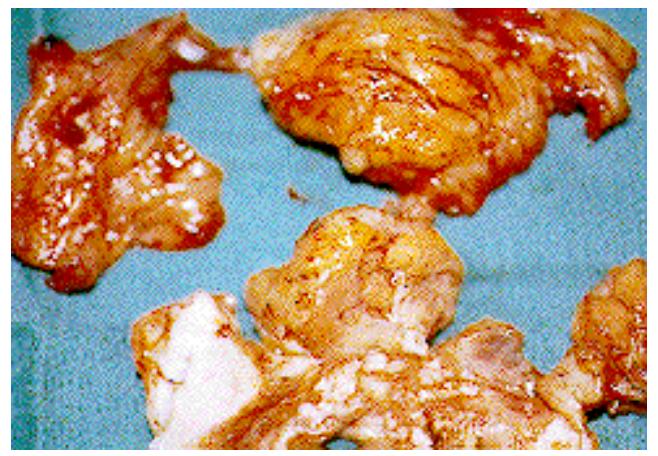

Figure 15) Breast tissue removed from the patient in Figure 8, showing calcified globules of silicone scattered throughout the tissue

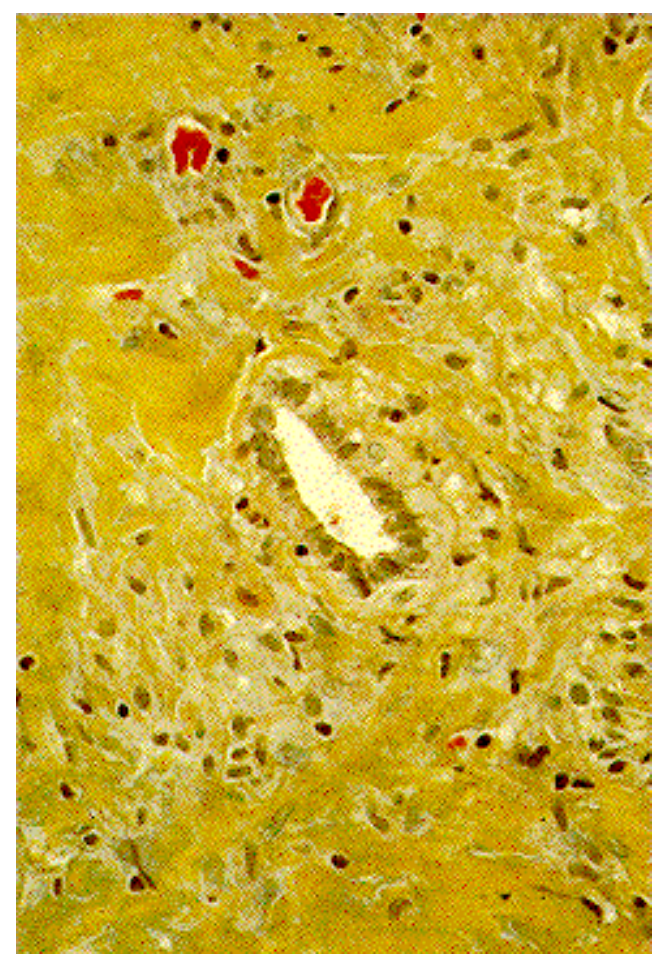

Figure 14) Histological section of the mass shown in Figures 12 and 13 shows a cystic mass with epithelial lining. High magnification showed several foamy histiocytes within the tissue, with breast ductal tissue centrally (WHO stain x250). This cystic mass therefore appeared to develop from secretory cells of breast tissue

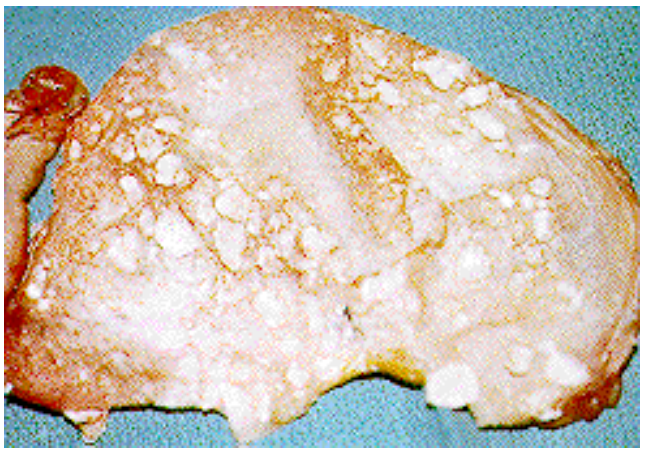

Figure 16) Calcified capsule of patient in Figure 10, with calcified plaques corresponding to the areas of stipling on mammography

Figure 11 shows a large calcified mass posteriorly in breast tissue. The patient's silicone gel implants had been removed five years previously, but her calcified capsules were left in situ. She had requested that they not be removed, to avoid a secondary 
deformity. Over the subsequent five years, this area of calcification had not decreased in size. She continued to present with a firm, hard, tender, mass in this breast. She agreed to have the calcified capsule removed, because it could interfere with future tumour detection.

Figure 12 shows the mammogram of a patient whose silicone gel breast implants had been removed two years previously. Her capsules had been left in situ. She presented with a firm, tender mass in the upper aspect of her left breast. Her mammogram revealed a dense spiculated mass, $5 \mathrm{~cm}$ in diameter, located deep in the breast tissue. This was interpreted by the radiologist as "very suggestive of malignancy", and a biopsy was recommended.

At exploration, a large, dense, firm, white, capsule-covered cystic mass was encountered, embedded within scar tissue. When the thick wall was opened, the cystic cavity (Figure 13) contained about $50 \mathrm{~mL}$ of a brown, watery, serous fluid. The capsule and adjacent scar tissue were completely resected. Histological section showed a cystic mass with epithelial lining. High magnification showed several foamy histiocytes within the tissue, with breast ductal tissue centrally (Figure 14). This secretory mass therefore appeared to rise from secretory ductal cells of breast tissue.

\section{DISCUSSION}

Mammography is not accurate enough to predict implant rupture in the majority of patients. Recent studies have demonstrated a sensitivity rate of only $11 \%$ and $16.2 \%$ $(4,5)$. This is particularly significant, because about $80 \%$ of all silicone gel breast implants inserted between 1973 and 1986 are currently thought to be ruptured $(5,6)$. In the present study, implant rupture was likely if mammography showed large areas of implant herniation or globules suggesting silicone outside the margin of the implant. Implant herniation has been reported in $17 \%$ of a series of screening mammograms in 350 patients (7). However, implant rupture was not assessed clinically in those patients. In the present study, if the size of the area of implant herniation was small, implant rupture was uncertain. Some implants were ruptured (Figures 2,3) and some were not (Figure 1). However, all four patients with large areas of implant herniation demonstrated ruptured implants (Figures 4,5) at the site of the herniation. Similarly, in the present study, all patients demonstrating silicone globules on mammography, lying outside the margins of the implant, proved to have ruptured implants.

Mammography was helpful to detect capsular calcification in patients with silicone gel implants. Calcification presented as areas of stipling on mammography and xeromammography. Because capsular calcification can interfere with early tumour detection and diagnosis, it should generally be resected at the time of implant removal. This resection requires further planning, patient discussion (concerning possible secondary deformity), and operative time.

Guinea pig studies published in 1973 (11) demonstrated that capsules surrounding implanted silicone elastomer blocks resolved within four weeks following removal of the blocks. This study has prompted many surgeons to leave capsules in place when implants are removed, to avoid the morbidity, possible deformity, and expense of total capsulectomy. Recent evidence, however, has suggested that uneventful capsule resolution may not always occur. Several potential problems have been demonstrated from retained capsules (12). 
In this study, mammography was helpful in diagnosing complications from retained breast capsules. In one patient, a retained capsule resulted in a spiculated mass, suspicious for carcinoma (Figure 12), that proved to be a benign cystic cavity (Figure 13), which appeared to develop from the secretory cells of breast tissue (Figure 14). In another patient, a large area of dense capsular calcification had persisted five years after implant removal (Figure 11).

\section{CONCLUSION}

Mammography is not able to predict accurately implant rupture in most patients. Its sensitivity rate is only 11 to $16 \%$. However, two mammographic findings appear to suggest implant rupture: the appearance of large areas of implant herniation, and the appearance of silicone globules lying outside the margins of the implant. Mammography is also helpful to detect capsular calcification and to assess complications of retained breast implant capsules.

ACKNOWLEDGEMENT: This research was funded by a Medical Research Council of Canada University Industry Grant

\section{REFERENCES}

1. Haynes H, Vandergrift J, Diner WC. Mammography and breast implants. Plast Reconstr Surg 1988;82:1-6.

2. Eklund GW, Bushy RC, Miller SH, et al. Improved imaging of the augmented breast. AJR 1988;151:469-73.

3. Hall RM, Homer MJ, D'Orsi CJ, et al. Mammography of the augmented breast. AJR 1989;153:1098-99.

4. Bassett LW, Brenner RJ. Consideration when imaging women with breast implants. AJR 1992;159:979-81.

5. Robinson OG, Bradley EL, Wilson DS. Analysis of explanted silicone implants: a report of 300 cases. Ann Plast Surg 1995;34:1-7.

6. Peters WJ. The rupture of silicone-gel breast implants. Ann Plast Surg 1994;33:462-3.

7. Destouet JM, Monsees BS, Oser RF, et al. Screening mammography in 350 women with breast implants; prevalence and findings of implant complications. AJR 1992;159:973-8.

8. Steinbach BG, Hardt NS, Abbitt. Mammography: breast implants - types, complications, and adjacent breast pathology. Curr Probl Diagn Radiol 1993;39-86.

9. Ganott MA, Harris KM, Ilkhanipour ZS, et al. Augmentation mammoplasty: normal and abnormal findings with mammography and ultrasound. Radiographics 1992;12:28195.

10. Peters WJ, Smith DC. Calcification of breast implant capsules; incidence, diagnosis and contributing factors. Ann Plast Surg 1995;34:8-11.

11. Thomson HG. The fate of the pseudosheath pocket around silicone implants. Plast Reconstr Surg 1973;51:667-72.

12. Hardt NS, Yu L, LaTorre G, et al. Complications related to retained breast implant capsules. Plast Reconstr Surg 1995;95:364-71. 